\title{
Araña, otra lógica. La escritura como urdimbre en Chantal Maillard
}

\author{
Spider, a different logic. \\ Writing as a mesh in Chantal Maillard
}

\author{
LOLA NIETO ALARCÓN \\ Universidad de Barcelona (España)
}

Recibido: 13-9-2012

Aprobado definitivamente: 24-1-2013

\section{RESUMEN}

La estructura desdoblada que adopta habitualmente la escritura de Chantal Maillard tiene un sentido intenso en el poemario Hilos. Este libro, que en parte surge como segregación del diario Husos, despliega una lógica estética contraria a toda interpretación metafísica. Para ello, los poemas crecen como ecos unos de otros y como reflejos de fragmentos de otros libros de la autora. En Hilos, la escritura teje una malla o red cuyos vórtices dibujan el mapa de un Texto en que obras de otras manifestaciones artísticas (Gego), filosóficas (Derrida) o mitológicas (Kālī) vienen a explicar su urdimbre.

\section{PALABRAS CLAVE \\ CHANTAL MAILLARD, ESTÉTICA, GEGO, DERRIDA, KĀLĪ}

\section{ABSTRACT}

The split structure in which Chantal Maillard's writing are regularly framed, has an intense sense in the poems in Hilos. This book, which comes as a segregation of the diary Husos, displays an aesthetic logic opposed to metaphysics. The poems are written as echoes and as reflections of other fragments of other Maillard's books. In Hilos, the writing is a mesh or a network whose 
vortices draw the map of a Text explained by other artistic works (Gego), philosophical works (Derrida) or mythological expressions (Kālī).

KEY WORDS

CHANTAL MAILLARD, AESTHETICS, GEGO, DERRIDA, KĀLI

\section{OTRA LÓGICA}

La escritura de Chantal Maillard se articula en estructuras sostenidas por el desdoblamiento. Muchos de sus libros crecen a partir de un andamiaje díptico: Poemas a mi muerte, Conjuros, Lógica borrosa, Matar a Platón o Hilos se dividen en dos partes a un tiempo autónomas y dependientes. En otros casos, como Husos y también Matar a Platón, el texto se bifurca en dos fugas o registros, dividido en el cuerpo principal de la escritura y notas al margen o subtítulos. Pero esto no es todo. En un nivel textual distinto, se advierten otros juegos de espejos que permiten entender las trayectorias que anudan la obra entera de la autora. Me refiero a las reelaboraciones: la transformación poética, en los poemarios, de fragmentos de prosa de los diarios. Probablemente, el caso más sintomático es el que acontece entre Husos e Hilos, ya que en este poemario toda una sección (la más larga, titulada «Poemas-husos») está constituida por 24 poemas que son en realidad versiones poéticas de párrafos del diario. Estas reelaboraciones no sólo sugieren un desmantelamiento de los géneros literarios, también proponen entender la escritura como una malla, un palimpsesto vivo, una urdimbre de permutaciones o casi repeticiones. Asimismo y si ampliamos el encuadre, ahondan en este sentido las correspondencias entre las dos modalidades que la escritura de Maillard adopta. Ensayo y creación, filosofía y poesía funcionan como actitudes artísticas que se entrelazan, abordando las mismas preocupaciones pero desde tonos distintos.

El desdoblamiento, por tanto, se produce en muy diversos planos textuales en la obra de Maillard y, en cualquiera de sus opciones, es siempre un elemento clave para la construcción de sentido. Por una parte, los desdoblamientos, cuando acontecen en el marco interno de un libro, tienen por cometido resquebrajar el significado, impedir que un texto cuente con una interpretación unívoca. El juego de correlatos entre las partes o entre los registros intercepta el sentido unidireccional y amplía los flujos semánticos a connotaciones inauditas y siempre desencajadas. Por otro lado, cuando se advierten relacionando obras, funcionan como miguitas de pan que de libro en libro esbozan caminos de huellas haciendo de la escritura una retícula elástica de variaciones que no cualquier lector puede disfrutar plenamente, tan sólo aquel entregado a la labor detectivesca. 
Los desdoblamientos, en definitiva, esquirlan la lógica clásica del significado a la vez que convierten la repetición de motivos en argumento. Ambos aspectos están íntimamente vinculados.

Por todo esto, no es arriesgado considerar que los desdoblamientos actúan como marcas discursivas que evidencian la estructura rizomática -según Deleuze diría- que, por una parte, organiza cada uno de los libros de la autora y que, por otra, confecciona la red conjunta en que todos ellos se interrelacionan, al modo en que los vórtices de una tela de araña están potencialmente conectados. Así pues, rizoma al cuadrado: en (en cada libro se adivina una estructura interna rizomática) y entre (entre todos ellos conforman un sistema rizomáticamente ritmado). Incluso me atrevería a rectificar y decir: rizoma al cubo, porque de estas estructuras, interna y externa, que acomodan la materia literaria se desprende otra que repercute en la elaboración lingüística. Y es que el lenguaje también se contagia de esta modulación y acaba formando haces semánticos, sintácticos y gramaticales cuyos sentidos, nunca zanjados, se adscriben a la apertura de la circunstancia y a la transformación del proceso. Una retícula de signos se despliega metafóricamente -la metáfora es el movimiento del rizoma- en cada libro y de libro en libro, mostrando las contorsiones de la particular danza que las palabras bailan en la escritura de Chantal Maillard.

\section{LOS HILOS DE LA DANZA}

En el poemario Hilos (2007), un libro fractal y surgido en parte como segregación de Husos, las series de desdoblamientos se multiplican. Así empieza el segundo poema, titulado «Hilos», igual que el conjunto del poemario, lo que propicia la primera duplicidad:

$$
\begin{aligned}
& \text { Permanecer - ¿permanecer?- la carne } \\
& \text { herida. Hay cicatriz. }
\end{aligned}
$$

Y en la parte final, leemos:

Quedar en lo reconocible.

-¿Quedar?- Permanecer. Ya dije

permanecer. Ya pregunté.

En un mismo poema se hace referencia explícita a ese poema, de modo que se incurre en una suerte de autocita que pone en evidencia la trama reflexiva de la escritura y la representación de todo acto escriturario. ${ }^{1}$ En Hilos, este tipo de

1 En Hilos, estas afirmaciones tienen un sentido doble, ya que los poemas de la primera 
entramado no sólo se detecta en el seno de los poemas, también se produce entre poemas. En el que da inicio al poemario, titulado «Uno», escribe Maillard:

\author{
Partir es dar pasos fuera. \\ Fuera de la habitación. \\ De la mente, no: \\ no hay. Hay hilo.
}
Y en el siguiente poema, «Hilos»-el mismo recién mencionado-, encontramos:

Partir es dar pasos fuera.

Fuera de la habitación.

De la mente, no. -iMente?-

Ya pregunté. Y no hay. Hay hilo.

Pero aquí no se detienen los eslabones de la cadena. En otra sección de la primera parte, la que agrupa cinco poemas bajo el epígrafe «Calma», en uno de ellos, el que empieza «La palma. Mano hacia arriba», la autora dice:
Avanzar es dar pasos fuera.
Aunque eso ya lo dije en alguna
parte, ¿o era partir?, partir es
dar pasos fuera. Es igual.

Se enlazan así dos poemas de una misma sección (la titulada «Poemashusos») y éstos con uno de otra («Calma»). Este desdoblamiento de versos no es sólo una manera de conectar distintos momentos del libro, es sobre todo la estrategia retórica para señalar la condicionalidad de los hechos de escritura, los cuales, rimando entre sí, se ensartan en la lógica del texto.

Una consecuencia relevante de estas redes de convocaciones es que el lenguaje se desmarca hasta alcanzar un puesto protagonista. Se dice y se desdice, se afirma y se niega, por tanto, se desestabiliza, se cuestiona y se inflexiona pero, sobre todo, con estos ejercicios, se convierte en objeto de sí mismo, en su única y misma referencia: todo sucede en el lenguaje, todo acontece en un plano lingüístico, por tanto, lógico. En Hilos, «los poemas no representan nada, se representan ante el lector», de modo que «no hay objeto al que trasladar la acción del verbo» (V. Trueba 2009, p.194). Desaparece, entonces, el sujeto ya 
que resulta imposible encomendarle una retahíla de infinitivos. Escribe Maillard en el poema «El punto»:

Sopesar.

Sentir.

Sentirse.

Entonces el cansancio.

El de sentirse. Otra vez.

Elegir escribir. Para situarse.

En el punto de mira.

Concentrarse. En el punto.

Decir punto. Punto.

Escribirlo. Escribir escribirlo.

Escribir miento.

Imposible escribir el punto. El

cansancio.

Decir cansancio.

Dejar de escribir.

Como acertadamente señala Virginia Trueba, «el único verbo conjugado en el poema es significativamente "miento", en su doble sentido de "mentir" y "mentar"» (2009, p. 196), porque mentar es mentir cuando se conjuga en primera persona. En unas páginas dedicadas a la literatura de Blanchot, Foucault sostiene:

El «hablo» funciona a contrapelo del «pienso». Éste conducía en efecto a la certidumbre indudable del Yo y de su existencia; aquél, por el contrario, aleja, dispersa, borra esta existencia y no conserva de ella más que su emplazamiento vacío. El pensamiento del pensamiento, toda una tradición más antigua que la filosofía nos ha enseñado que nos conducía a la interioridad más profunda. La palabra de la palabra nos conduce por la literatura, pero quizás también por otros caminos, a ese afuera donde desaparece el sujeto que habla. Sin duda es por esta razón por lo que la reflexión occidental no se ha decidido durante tanto tiempo a pensar el ser del lenguaje: como si presintiera el peligro que haría correr a la evidencia del «existo» la experiencia desnuda del lenguaje. (2008, pp. 13-14). 
En el poema «El punto», el desdoblamiento es el de la acción que no se consigue llevar a cabo: escribir. Es una representación de la fallida representación de la escritura, por tanto, del habla, por tanto, del sujeto que (se) dice tras la voz que habla y que es sentido como un mero pliegue gramatical. Pulverizar las ficciones del lenguaje y desmantelar su gramática -que, como advertía Nietzsche, es la argamasa que levanta toda idea metafísica- con esas mismas herramientas, esto es, con el lenguaje y su gramática, tiene consecuencias evidentes: la escritura que de esta coyuntura emerge sólo puede ser su propia deconstrucción.

Contra el totalitarismo de los conceptos últimos y, en consecuencia, a la tarea deconstructiva de éstos, Maillard dedica varios poemas de Hilos. En la sección «El cuarto», encontramos éste:

Siempre están los hilos.

La maraña de hilos

que la memoria ensambla por

analogía. De no ser

por esos hilos,

la existencia - ¿existencia?-

todo sería un cúmulo de

fragmentos - ¿fragmentos?-,

bueno, destellos si se quiere.

Todo sería destellos. Inconexos

-inconexo: palabra sin

referente. Vacía. Tanto

como infinito, inaudito,

inmutable, inextenso,

ilimitado, etcétera.

Etcétera también.

Como los atributos

de Dios. Palabras que entorpecen

las cosas en lo dicho.

Inconexo es ver algo conectado

a otro algo del que luego

se separa. Inconexo es decir la

distancia sin perder de vista

lo contrario. Imposible

entender sin imagen-. Así pues, 


\author{
los hilos. La maraña. Eso, \\ al despertar. La cabeza, por tanto, \\ en la almohada. Los ojos \\ a veces entreabiertos. Para \\ la claridad. A veces \\ cerrados. Estirando los hilos.
}

Como en tantos otros textos del poemario que podrían servir de ejemplo, aquí también los guiones abren un marco para la reflexión dentro del propio poema, cambiando así su curso, su ritmo y su significado. ¿Qué son los hilos? De algún modo, a esta pregunta intenta responder la escritura, que se inicia con voluntad de definición. Sin embargo, no cae en su propia trampa de lenguaje y advierte que uno de los términos empleados incurre en una incongruencia lógica. Se despliega entonces una escritura entre guiones -escritura al margen- que, no obstante, condensa el sentido del poema.

En «Hilos», de la sección «Poemas-husos», también se detecta esta advertencia acerca del hueco referencial que la fantasía metafísica inocula sobre las estructuras conceptuales:

$$
\begin{aligned}
& \text { Ciertas palabras se utilizan } \\
& \text { en vez de otras, dicen. Cuando } \\
& \text { no hay palabras suficientes. } \\
& \text { Mejor cuando no hay } \\
& \text { cosa. }
\end{aligned}
$$

Los derrumbes teleológicos y, por tanto, lingüísticos rastreables en Hilos tienen equivalencias en otros lugares de la escritura de Maillard. En el diario Husos, por ejemplo, ciertos párrafos parecen en sintonía con las ideas de estas estrofas. $^{2}$ Escribe Maillard:

La idea no. No hay. Sólo hay imagen. Imagen verbal. Imagen de la palabra escrita. Como el infinito. Imposible, la imagen de infinito. Salvo la imagen (metáfora) de algo que disminuye hasta perderse de vista. Sólo la disminución. Finita. Como la muerte. Imposible imaginarla (2006, p. 87)

2 Obviamente, los fragmentos de Husos que protagonizan las reelaboraciones de Hilos (antes mencionadas), en cuanto versiones o ecos, abordan exactamente los mismos temas. Pero no es mi intención ocuparme aquí de las reelaboraciones, sino de las resonancias que a un nivel más amplio y general se producen en la escritura de Maillard y que permiten aproximarse a ella como si de una urdimbre se tratara. 
Desde otra perspectiva, el diario plantea la misma cuestión que sugerían los versos de Hilos: ¿cuál es el sentido del lenguaje? De ambos libros se deduce una misma tesis: descendido de su pedestal ontológico y metafísico, el lenguaje se comprende como una herramienta epistemológica cuyos axiomas gramaticales no deben rebasar el espacio lógico que su propio sistema dispone. Así pues, las ideas, los conceptos últimos (todo, nada, infinito, verdad, origen, muerte...) no deberían desvincularse de la necesidad lógica que los produce. Infinito surge como opuesto a finito. Conocemos cosas finitas pero no cosas infinitas; sin embargo, somos capaces de pensarlas. La confusión surge cuando concedemos esencia a lo que podemos pensar por el mero hecho de que puede ser pensado. Es así como suponemos que existe algo cuya palabra hemos inventado por (d)efecto lógico. Sin embargo, la substancia de ese algo topa con un vacío referencial. Deconstruir el lenguaje es detectar y eliminar estos fantasmas que habiéndolos creado nos los hemos creído. El lenguaje no deja por ello de ser una ficción (lo es en cuanto lo consideramos un sistema representacional de signos), pero se abre una distancia decisiva entre sostener que los hechos de lenguaje son a considerar que los hechos de lenguaje llaman.

Estas ideas, que Maillard desarrolla en su escritura creativa, también ocupan espacios determinantes en los ensayos, generando así reflejos o desdoblamientos entre las dos actitudes de escritura que la autora practica. En un artículo de Contra el arte, titulado «Desde la ignorancia», Maillard expresa bajo un tono ensayístico el contenido de las citas transcritas anteriormente:

En el ámbito conceptual, cualquier cosa es posible; puede darse en el concepto lo que sería imposible que se diera en el orden real. En el concepto, cualquiera podría, sin problema, aceptar el Dios del racionalismo: el ente de razón que ocupa la cúspide en la elaboración de las síntesis. [...] Elaboramos la síntesis y, luego, la nombramos. Una vez nombrada parece que adquiere existencia propia. [...] Estamos demasiado familiarizados con la utilización de esos comodines que sirven para justificar todo aquello que convenga. (2009, pp. 166-167).

Estas redes de palabras para cuestionar el estatus de las palabras nos han llevado de los poemas de Hilos a fragmentos de Husos y finalmente a un artículo de Contra el arte. Ésta tan sólo es una de las posibles trayectorias, uno de los caminos de conexiones que la escritura de Maillard dispone para que el lector trace. Toda su obra es una reformulación desde distintas modulaciones de las mismas constantes, de modo que los cauces que la alimentan resuenan, replicándose, a lo largo de ella.

Revisados ya algunos casos de desdoblamiento en los poemas de Hilos, entre sus poemas y también con respecto a otros libros de la autora, parece oportuno ahora dedicar un tiempo a las correspondencias que se descubren entre las dos partes del poemario, es decir, entre Hilos, formada por ocho secciones, 
y Cual. No hay duda de que el personaje de la segunda parte es un ser surgido de los desechos de la escritura tras haber sido sometida a la teoría-método de la primera. En efecto -y no es una coincidencia-, Cual irrumpe tras la sección de Hilos «La luz, el aire, el pájaro», que constituye una poética. De este modo, es como si los poemas de Cual surgieran de acuerdo a la poética con que Hilos se cierra, como si ellos fueran la única praxis posible de la escritura después de la furia deconstructiva: como si Cual representara la única actitud poética honesta después de la vorágine dinamitera. Tras la demolición lingüística de Hilos, se divisa un espacio, un reducto pequeño desde donde es posible volver a hablar pero sólo con un lenguaje desarticulado de la metafísica que lo articulaba, un lenguaje que en última instancia es una especie de carcajada catártica ( «Sentado en una piedra, Cual / riendo», 2007, p. 161) que señala el desmantelamiento del aparato teleológico de la gramática. Cual se ríe, y su risa irónica y compasiva, sarcástica y tierna es la de un mendigo lúcido y triste que recoge restos: palabras diminutas (casi-palabras) para decir el misterio y decirnos. La escritura de Hilos, aunque apresuradamente nos pueda parecer un final, es un inicio, otro inicio.

En el retrato de Cual, dos poemas recuerdan su genealogía:

$[\ldots]$

Cual excedido.

Ofuscado. Trémulo.

Dispersos, los hilos.

Sin hilo, es probable.

Líneas de suspensión tan sólo.

Puntos. De fuga.

Cual sin uñas que morder.

Treinta años mordiendo.

$\mathrm{Al}$ menos.

Y:

Hubo un tiempo, tal vez, en que todo era un punto.

No una concentración:

sin Cuales en el centro, no era necesario.

Y tampoco lo era cuando el punto

se ensanchó,

si es que ocurrió de esta manera. 


\author{
El exceso empezó \\ con el espacio interno. Allí \\ las idas y venidas, las \\ direcciones, los límites \\ y el impulso, \\ la miseria de cada Cual \\ expandida en los husos.
}

Los husos y los hilos describen las modulaciones mentales de Cual. Este vínculo con la escritura anterior (con la primera parte de Hilos pero también con Husos, remarcando así que el poemario y el diario son libros tándem) también se descubre en otro rasgo de su etopeya. Como apunta Trueba, «el aire es el elemento fundamental de toda esta parte. El aire, la condición de posibilidad del suceder» (2009, p. 199). Y en este sentido, en un poema significativo, Cual aparece descrito bajo estos términos:

Ser pájaro.

Cual considerando.

Andar desnudo. Las heridas

cauterizadas por el aire.

Entre las plumas, disimuladas.

Cuerpo sin carga, movimiento.

Ser de vuelo. Ser

pájaro.

En el último fragmento de Husos, Maillard había escrito:

Liviano como los pájaros, mineral como las piedras, bajo el flujo de las palabras que reniegan, sobrellevándolas como la corriente de un río a las barcas y a los remos que la hienden, así el gozo, bendiciendo a quien de él se defiende, así

el gozo.

Creo que la alusión a la liviandad de los pájaros en el diario es la misma que se recoge en el poema de Cual. ${ }^{3}$ Creo que de esta manera -que de alguna

3 Salvo por la ironía. En la última parte del poema de Cual (no transcrita aquí) surge un 
manera- se pretende poner en relación el gozo final de Husos con el personaje de la segunda parte de Hilos. Con esto no quiero decir que considere a Cual un ser regresado al estado prediscursivo de la infancia, que es el sentido que el gozo guarda en el diario. No ha regresado, pero ha desaprendido: se ha empobrecido y ha menguado de espíritu, de intenciones. Cual no ha vuelto al gozo de la infancia (volver a un estado previo al lingüístico sería algo a fin de cuentas imposible), pero es un ser que -cargando con el peso de su (auto)conciencia hiriente y herida-aspira a la calma de una actitud estética y ética: ejercitarse en la reducción de los estados mentales con los que nos identificamos, o al menos no perder de vista su condición ilusoria. Vivir si no en el gozo - ¿perdido?-, en la observación de lo que le impide estar en él.

\section{AraÑAS}

Maillard cita estas palabras de las escrituras upanishádicas en un trabajo incluido en Contra el arte: «Así como la araña segrega su hilo y lo recoge [...], así el universo surge del imperecedero (Mundaka Upanisad, 1. 1. 7)». Y comenta:

Dos grandes metáforas, el hilo de las Parcas y el hilo de la araña, muestran la diferencia entre la cosmovisión europea y la india. [...] El hilo de la metáfora griega representa la existencia personal; el de la metáfora india, en cambio, alude a la existencia del universo o, mejor dicho, de uno de ellos. Así como es segregado por la araña, cada universo es reabsorbido por ella. La araña es el brahman y el universo, un latido, una exhalación, un hilo de saliva. La historia de un individuo, su existencia, es bien poco, si se contempla desde ahí. (2009, pp. 283-284).

Por eso, en uno de los poemas de Hilos, escribe:
Hilemos, señores, es tiempo de relevar a las Parcas.

Por eso, también, la estructura de todo el libro -como he intentado mostrar en las páginas anteriores- sugiere la forma de una enorme tela de araña. Los hilos de Hilos, esto es, los desdoblamientos escenifican la tarea arácnida que la escritura desarrolla y, por extensión, representan la red que urde la obra entera de Maillard, y a la que el poemario viene a hacer crecer enmarañándose.

Sin embargo, habría que precisar una diferencia importante. Y es que, aunque en Hilos la escritura se puede comparar con la acción tejedora de la

sentido irónico que en el fragmento de Husos no aparece. 
araña, la tela de palabras del poemario prescinde de centro, es decir, no conforma una urdimbre radial sino reticular, y de ahí que las estructuras sintácticas y semánticas que segregan los hilos escriturarios de Maillard se aproximen asombrosamente a las tramas de alambre de las esculturas de Gego.

Gertrud Goldschmidt (Gego) nació en Hamburgo en 1912. Huyendo de la Segunda Guerra Mundial viajó a Venezuela en 1939 donde adquirió la nacionalidad de ese país años más tarde. Jamás volvió a Alemania. De profesión arquitecta, en la década de los cincuenta se aventuró en la técnica del dibujo en acuarelas, grabados monotipos y xilografías. Fue en esa misma época cuando empezó a concebir formas tridimensionales con papel. Y enseguida llegaron las esculturas de hierro. Gego siempre diseñó sus obras dentro de grupos de series: los Bichos, los Chorros, las Esferas, los Troncos, las Tejeduras, las Reticuláreas..., de modo que las obras incluidas en estos conjuntos se identifican numéricamente y suelen estar construidas con años de diferencia entre sí. Gego fue engrosando las series a lo largo de toda su vida artística y de esta manera las esculturas se articulan siguiendo leyes arácnidas particulares: ninguna es central en su serie y éstas jamás se cierran.

Como las obras de Gego, algunos poemas de Hilos también se presentan bajo forma serializada. Por ejemplo, encontramos: «El tema I», «El tema II», «El tema III» y el «Tema IV». O: «Lo irremediable I» y «Lo irremediable II». Asimismo, algunos títulos están repetidos. «Sin» es el epígrafe que encabeza dos poemas, el de la página 19 y el de la 59. De idéntico modo, «Estrategias» se titula el poema de la página 37 y el de la 41 . No son repeticiones aunque las sugieren otros títulos, como «Más de uno» en referencia directa al poema «Uno», así como «Y también» $\mathrm{y}$ «Cf.». Por último, dos secciones, la tercera y la quinta de la primera parte, se llaman igual: «Irse».

La serialización procura, tanto en la obra escultórica de Gego como en la literaria de Maillard, un mismo cometido, aquél con el que esta práctica se inició en las vanguardias: desactivar el concepto de mímesis en arte. Pero con todo, la artista venezolana no limita únicamente a estos efectos dicho procedimiento compositivo. En ocasiones, sus esculturas son el resultado de una simbiosis entre obras de series distintas. En otras, obras de una misma serie o de series diferentes se presentan juntas, de modo que constituyen creaciones originales cuyo sentido es autónomo y dependiente al mismo tiempo: son obras compuestas a partir de la yuxtaposición y sutura de otras obras y de ahí la simultánea autonomía y condicionalidad entre ellas. Este tipo de desdoblamientos en una obra y entre obras así como la relación ambivalente de dependencia/independencia que se genera son puntos de contacto entre la actividad escultórica de Gego y la literaria de Maillard.

Con estas estrategias de creación, Gego -también Maillard- traslada la acción artística al modo en que se articulan las partes de una obra proponiendo 
una particular concepción del objeto de arte. Sus esculturas no se ofrecen como un todo cerrado y mostrado en estricta perfección, por el contrario, se perciben como haces de elementos fractales interrelacionados unos con otros, de cuyo contacto circunstancial y en perpetua transformación se desprende el alcance estético. El espectador, claro, viene a ocupar un papel activo y determinante en la construcción de sentido.

La Reticulárea, que en 1969 se expuso por primera vez en el Museo de Bellas Artes de Caracas, es una de sus obras más referenciadas y significó el reconocimiento público y crítico de Gego. Las piezas de hierro encadenan una malla que se extiende por toda la sala trepando paredes y techos, inmiscuyéndose en rincones y ranuras. La repetición es la fuerza motriz que genera las secuencias. Segmentos de alambre de distintas dimensiones se enlazan configurando celdas generalmente triangulares. Los vórtices son los puntos de unión y ensamblaje entre ellas y, asimismo, son los núcleos que posibilitan su infinita prolongación. A diferencia de las otras esculturas, la urdimbre de la Reticulárea no origina una figura (esfera, tronco, chorro...) sino que se acomoda al espacio en el que surge, como una tela de araña se ajusta a las esquinas o huecos en que crece. Su disposición depende del lugar en el que está. Es según al contexto en el que se expande.

El espectador de la Reticulárea no la observa, entra en ella, camina, se mueve y contornea, oscila al ritmo de sus formas, dejándose absorber por las modulaciones de la red. Del mismo modo que los insectos quedan atrapados en los filamentos pegajosos de la trampa de una araña, así, quien se aventura a penetrar en la obra de Gego pacta su abducción a causa de la pérdida de coordenadas espaciales que ésta provoca. Dicho efecto se obtiene principalmente por las reelaboraciones que constituyen su estructura. Y es que las celdas, aunque constituyen unidades muy parecidas, nunca son iguales: poseen distintos tamaños, densidades y proporciones. La extraordinaria irregularidad dentro de la aparente y estricta regularidad desencaja los puntos de observación. Una inmensa cantidad de celdas en superposición paraláctica y orientación escindida genera un entorno que excede nuestra capacidad de síntesis observadora. La mirada no puede abarcar de una vez y como conjunto la escultura de la Reticulárea. El espectador -como sucede en las pinturas zen chinas- pierde su posición de observador externo y totalizador, pierde, en definitiva, su identidad de espectador para sumergirse en el interior de la obra y formar parte de ella, para abismarse en la abrumadora sintaxis de las (casi) repeticiones, que tanto recuerda a los «laberintos de intrincados motivos decorativos de distintas escalas, diseñados para extraviar la mirada, para crear una ligera sensación de vértigo propicio a la contemplación» (I.-A. Bois 2007, p. 51) de las construcciones sagradas de la arquitectura islámica. 


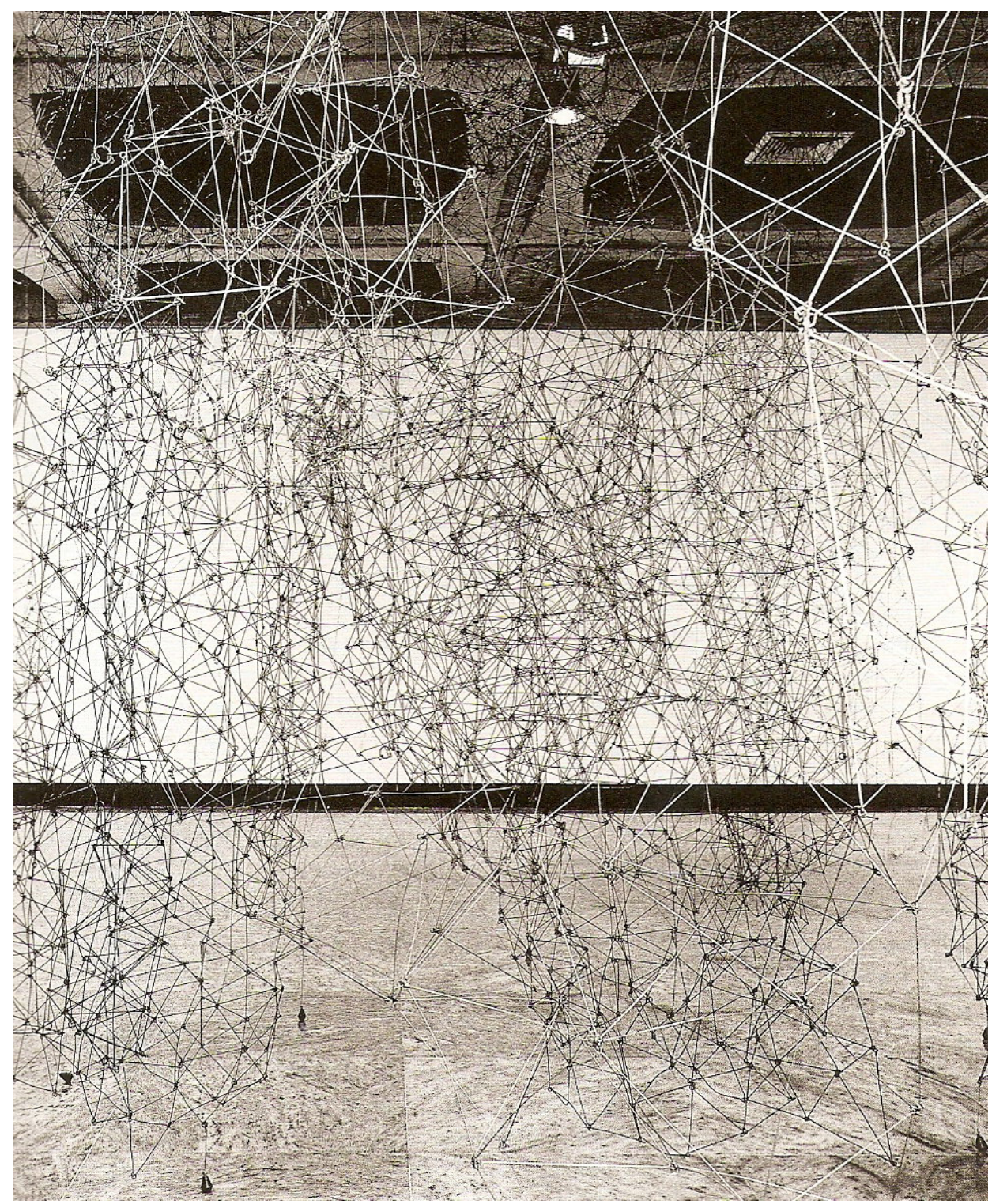

Fig. 1. Reticulárea. Museo de Bellas Artes de Caracas, 1969

Un dato significativo es que en todas las fotografías de la Reticulárea en las que aparecen espectadores, éstos siempre están en movimiento, como resiguiendo con la postura del cuerpo lo que los ojos miran. Es muy curiosa, 
en particular, la reacción de los niños, que acostumbran a corretear, jugar o incluso bailar dentro de la obra. Y es que de algún modo es como si intuyeran que para experimentar estéticamente la Reticulárea no basta con la mirada, no es suficiente ni adecuada una actitud observadora excluyente y excluida, sino que es preciso participar: observar, sí, pero con todo el cuerpo. Extrañamente, son como insectos liberados por la trampa.

Estos rasgos que caracterizan la obra de Gego y en especial su Reticulárea pueden servir para entender el sentido orgánico de la escritura de Maillard y, particularmente, la de Hilos. De hecho, creo que es muy interesante, en este sentido, prestar atención al dibujo que se incluye en el poemario. En la última página, como cierre, aparece una ilustración de Joaquín Ivars, titulada Aún, interpretación gráfica, cuya convergencia con la Reticulárea es, más que evidente, asombrosa.

Líneas de longitud diversa orientadas en diferentes direcciones sin perspectiva y unidas por varios ejes conforman una forma reticular y rizomática, potencialmente infinita, entre cuyos segmentos se intercalan palabras, en concreto, verbos en infinitivo: describir, decir, tentar, caer, trazar, conmover, vivir... Un detalle de este mismo dibujo, uno de los nódulos de unión, sirve para separar del resto -separar uniendo- dos de los poemas más relevantes de Cual, el que empieza «Cual junto a indignado» y el último, con el que termina el conjunto. Asimismo, en la cubierta del libro, aparece otro fragmento de la ilustración de Ivars. (Fig. 2)

Como su propio título explicita, la ilustración de Ivars es una «interpretación gráfica» de la red lingüística del poema «Aún» y por extensión de Hilos. Las líneas se despliegan como las hebras textuales del poemario o como los alambres de la Reticulárea. Quizá se pueda entender la discontinuidad de los trazos como las intermitencias del pensamiento y sus sacudidas, incluso, como la fragilidad-fuerte que tanto los hilos como los alambres atesoran, emulando asî la tensión de la tela de araña: su fuerza resulta de su flexibilidad, de la sutileza finísima pero multiplicada de los filamentos. 


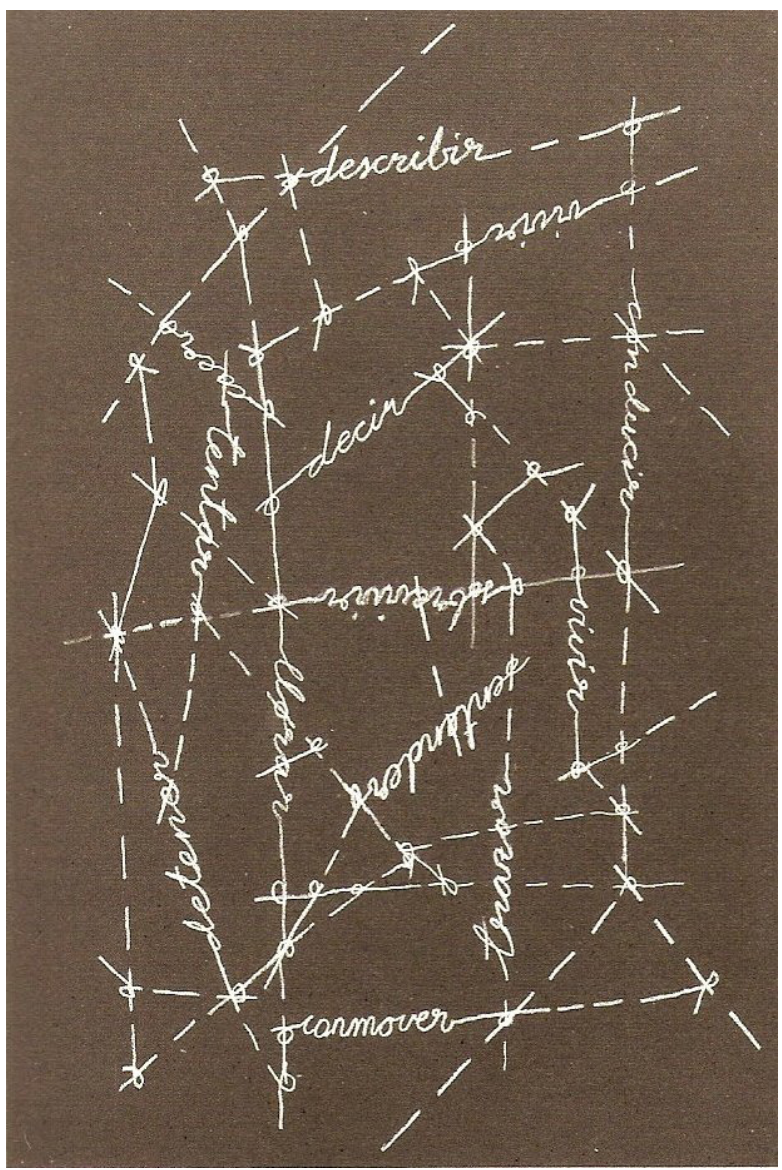

Fig. 2. Aún, interpretación gráfica de J. Ivars

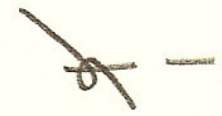

Fig. 3. Detalle que antecede dos poemas de Cual 


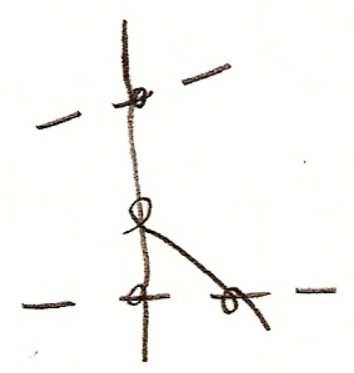

Fig. 4. Detalle de la cubierta de Hilos

Precisamente es esta multiplicidad arácnida (pero sin centro ni límite: arañasin-metafísica, araña-deconstruida) la que adopta Hilos en su lógica creativa y por la que los poemas se despliegan y expanden en una yuxtaposición interconectada de elementos-citas abierta ad infinitum. Aunque ciertas composiciones cobren importancia singular respecto al conjunto, la estructura de Hilos no privilegia la unidad sino el organismo y su engranaje. Maillard, como la araña con su tela -como Gego (la araña alámbrica) con sus esculturas- podría haber segregado más poemas o reabsorbido algunos. Precisamente es también esta multiplicidad magmática la que propicia un particular aturdimiento receptivo - muy similar a aquél que provoca la concatenación de celdas en la Reticulárea-, donde el lector se pierde, se desorienta, deja de saber cuántas veces leyó un mismo verso o si quizá nunca fue repetido, si un poema o algunas de sus secuencias ya aparecieron antes en otro poema o acaso nunca. Leer, en Hilos, significa releer, regresar constantemente a lo leído (que se transforma), volver las páginas para comprobar y embrollarse, caer en la madeja, caer en la cuenta de que «ser o no ser no es la cuestión, / la cuestión es saber deslizarse sin miedo / entre las superficies» (CH. Maillard 2004, p. 49). Saber deslizarse entre las superficies del texto implica no terminar de leer nunca. Dice Barthes: «la metáfora del Texto es la de la red» ${ }^{4}$ donde «el modelo de esta nueva mimesis

4 Curiosamente, la red es también la metáfora de la visión biológica actual de los seres vivos (por ejemplo, de las teorías organizativas neuronales) y, asimismo, la del tejido del universo que propone la astrofísica actual. Entender las conexiones neuronales y las galácticas en fuga rizomática equidista estas disciplinas -llamadas científicas- al arte, la filosofía, la literatura y demás disciplinas creativas, y viceversa. Esto demostraría (en mi opinión) que tanto unas como otras son inventos humanos y que éstos como tales se encuentran íntimamente ritmados en el curso de sus devenires y de sus descubrimientos. Se configuran de acuerdo a sus respectivos lenguajes -científicos, artísticos- de comprehensión pero según un mismo paradigma epistemológico. Se expanden en una textualidad donde los postulados astronómicos pueden entenderse como una cita de los postulados neurológicos, y éstos como una cita de los filosóficos, y éstos como una cita de los literarios... en definitiva, como citas unos de otros en un sentido (no unidireccional 
ya no es la aventura de un héroe, sino la propia aventura del significante: lo que le sucede» (2009, pp. 92 y 339).

Las redes de significantes de Hilos desmontan las ideas de origen y originalidad. De este modo, no sólo se neutralizan los planos discursivos internos sino también y muy singularmente los externos. Me explico. El verso que cierra el libro dice: «La orina del héroe se ha secado» (2007, p. 187) y, como apunta Trueba, su interés no sólo reside en «su contenido, que apela implícitamente a la necesidad de otro mito, de otra poesía, la de la comunidad, más allá, no obstante, de antiguos heroísmos. Es también su autoría: el verso pertenece a un poema de Blanca Varela. ¿Pertenece?, ¿a quién pertenece ya el verso?» (2009, p. 199). Este verso -que se encuentra en el poema «El capitán» recogido en Ese puerto existe - pertenece al texto, a la textualidad, al devenir del palimpsesto que entiende que no hay literatura sino escritura, que no hay autor sino habla y lenguaje.

La propia Maillard ha sugerido la posible vinculación entre este cauce creativo y una declinación femenina del pensamiento: «Frente al árbol de Porfirio obtenemos, siguiendo la terminología deleuziana, un rizoma, una red de elementos que se autoconstituyen y se destruyen siguiendo el ritmo vital del organismo que configuran, un organismo vivo que le debe la vida a la comunicación perpetua de sus partes. Este tipo de lenguaje capaz de jugar en la multiplicidad interactuante y viva del universo, capaz de combinar los diversos planos de la conciencia, lo real y lo onírico, lo real y lo posible, capaz, sobre todo, de tener en cuenta eso: lo posible, esta forma de lenguaje sería el más adecuado a lo que puede denominarse, hoy en día, una racionalidad "femenina"». (1998, p. 242)

Este otro lenguaje surgido desde otra vibración del pensamiento -vibración femenina, arácnida, anónima, textual, metafórica, rozando acaso lo mitológico en la articulación de su sentido- desarma uno de los bastiones impertérritos del logocentrismo: el sujeto.

\section{KĀLĪ, LA DIOSA DE LA DECONSTRUCCIÓN}

La escritura reticulárea de Maillard en Hilos sugiere, en definitiva, otra lógica: lógica-tela-de-araña, es decir, lógica que se sabe tal y por ende conoce su trabajo: la construcción y deconstrucción de discursos. Con esta otra lógica, consciente de sí, «desaparece el concepto [...] de estructura fuerte, estructura estable que imponía al pensamiento y a la existencia la tarea de fundarse, de establecerse en el dominio de lo que no evoluciona» (G. Vattimo 1986, p. 17). Entonces, el modelo teleológico de estructura céntrica se decanta hacia una forma lúdica «de sustituciones infinitas en la clausura de un conjunto finito» (Derrida 1989, p. 397), es decir, el sentido de la différance:

sino) interconectivo. 
El juego de las diferencias supone, en efecto, síntesis y remisiones que prohíben que en ningún momento, en ningún sentido, un elemento simple esté presente en sí mismo y no remita más que a sí mismo. [...] Este encadenamiento hace que cada «elemento»-fonema o grafema- se constituya a partir de la traza que han dejado en él otros elementos de la cadena o del sistema. Este encadenamiento, este tejido, es el texto que sólo se produce en la transformación de otro texto. (Derrida 1977, pp. 35-36).

La lógica arácnida de Hilos (lógica de los desdoblamientos que finalmente sirve para explicar toda la obra de Chantal Maillard) se puede entender, no hay duda, como una contigüidad con el pensamiento derridiano. Sin embargo, otro linaje parece más oportuno: Kālī, la diosa oscura de la cosmogonía hindú. ¿Podría acaso ser considerada la divinidad india una fuerza precursora de lo que siglos más tarde, en la época de la posmodernidad occidental, Derrida llama deconstrucción? Conozco los peligros de incurrir en un anacronismo y por eso, más que una identificación sin resquicios, propongo una comparación de ambos discursos - uno mitológico, otro analítico- desde el sesgo de sus concepciones epistémicas para desentrañar las convergencias, y ver cuánto de ellos se advierte en la obra de Maillard. Esta comparativa me perece pertinente, incluso necesaria, porque la actitud deconstructiva de la escritora, en Hilos y en el conjunto de su trabajo literario, está finalmente impregnada de la hermeneusis que destellan los atributos de la diosa guerrera. Aún diría más: Chantal Maillard entiende la figura de Kālī como metáfora de su quehacer escriturario y de ahí que su ímpetu de desprogramación metódica se deba, más que a un apego derridiano, a un ejercicio de empatía con la diosa de la India. O más precisamente: Maillard llega a los preceptos de la posmodernidad y en concreto del postestructuralismo por efecto de rodeo y empape de ciertas enseñanzas de la sabiduría antigua.

Kālī aparece reseñada directa o indirectamente en casi todos los libros de la autora. Su figura, más que una referencia culta encajada, es un ritmo incorporado. En Hilos, la palabra poemática de Chantal Maillard es la coreografía escrita de la danza terrible de la diosa: la escritura, al tiempo que se escribe, se desescribe, del mismo modo que Kālī destruye el mundo a la vez que construye el gesto de la propia destrucción.

En Diarios indios, Maillard dedica este fragmento lúcido a la diosa:

¡Qué difícil asumir la función de Kālī! ¡Qué pocos son capaces de ello! Kālī, la que he construido a partir de sus símbolos tradicionales. Mi Kālī... ¿La he construido? Realmente no. Mi Kālī es Kālī, uno de sus niveles, uno de los más abstractos tal vez, aquel en que lo epistemológico se identifica con lo ontológico, el conocimiento con el ser. Todo ser es ser conocido. Ser y conocimiento no se diferencian. Ser y pensar... Nada es primero. Ambos son la misma energía. Una energía que cons- 
truye, que no puede no construir. Incluso cuando destruye. Construye la idea de destrucción y destruye. Luego destruye la idea de destrucción.

Ahora, el círculo se cierra sobre el pensar que se piensa a sí mismo. Que se piensa como pensamiento, como fugacidad. El pensar se anula en el pensamiento de la fugacidad o la inconsistencia del pensar. Todo castillo - un castillo es un edificio mental en el que se ha llegado a habitar (es decir, creer)- es destruido con el instrumento que sirve para construir. (2005, pp. 87-88)

Cuando los dioses perdieron la guerra contra los demonios (los asūras), angustiados por devolver el equilibrio al universo, congregaron la fuerza de sus alientos para hacer surgir a Durga. Ésta, en mitad del combate, emanó de los pliegues fruncidos de su frente el cuerpo de Kālī, que se convirtió en la diosa de la oscuridad y en la energía de la desaparición. Kālī destruyó el mundo -un mundo-, contrajo a su unidad original la dispersión de las formas ilusorias (māyā) y dispuso el vacío necesario para crear de nuevo, otra vez, otro mundo (para más detalles del mito ver CH. Maillard Contra el arte pp. 265-270).

Éste es el ejercicio hermenéutico que Maillard propone recuperar para los procesos de la conciencia, la gran hacedora de mundos (mentales). En el segundo párrafo de la cita anterior creo que se encuentra la bisagra que permite establecer un puente entre la mirada cósmica que encarna la diosa hindú y la deconstrucción derridiana, porque en él Maillard entiende la acción de Kālī aplicada a los recovecos de la mente. Destruir -o deconstruir- un mundo es entonces deshacer los conceptos que lo han apuntalado detectando sus fallos lógicos, así pues, es desmontar desde su interior el mismo pensamiento que sirvió para levantarlo. Es en este sentido que la fuerza de Kālī, su descreimiento en las imágenes y los simulacros que conforman la realidad, esto es, su conciencia de las ficciones, se puede considerar una contrapartida mitológica de los discursos lógico-analíticos que prosperaron, en Occidente -y tras el impulso del empirismo anglosajón-, a partir de Wittgenstein.

Kālī no aboga por una destrucción absoluta y definitiva sino por eliminar un mundo que ha quedado desajustado tras una guerra, es decir, inservible en sus parámetros cognitivos. El tiempo, en la tradición india, es cíclico, no lineal, por eso a esta destrucción le sucederán otras, como otras la precedieron. En el gesto tántrico de la diosa se trasluce el ceño reflexivo que el pensamiento posmoderno llevó a cabo cuando dio en llamar -con Lyotard- meta-relatos a aquellos discursos que convertidos en creencias habían sostenido los sistemas filosóficos hasta entonces. No por ello dejaron de ser válidos, pero sí perdieron su privilegio de verdad. De este modo hay que entender las creaciones mundanas de la divinidad india: desde el sesgo de la verosimilitud y la funcionalidad de las obras de arte. 
¿Qué le ha quedado a la filosofía tras el desmantelamiento de la metafísica platónica? Los mundos de Kālī. Este fragmento de Filosofía en los días críticos es, de alguna manera, un manual de instrucciones que Maillard, siguiendo la estela fulgurante de la diosa, propone en esta nueva encrucijada:

Descreer. Descreer. Eliminar el lastre de todas las creencias. Ése es el umbral del vacío, la puerta que conduce al interior que es centro y superficie.

No os convenceré. No es un combate la enseñanza. Han venido a combatir, pero he aquí que el enemigo les dice: «No creáis nada de lo que os he dicho, no creáis lo que os cuento.» Ésta es la primera lección de filosofía; también será la última. Entre la primera y la última enseñaré lo que otros han pensado y han creído. Nadie puede entrar en el reino de la filosofía si no es sabiendo esta lección, la primera y la última. Ya no. Nunca más. Hemos creído demasiado. Hemos matado demasiado. Es hora de hacer limpieza. Que la nada espera a ser probada.

Y luego, desde la nada, todo. Todo ha de ser construido, por gusto o por utilidad, ya nunca más por creencia (2001, pp. 237-238).

Construir ahora sigue siendo posible -Wittgenstein acabó por concluir que se podía hablar de cualquier cosa, pero sabiendo que ninguna cosa escapa a la lógica que la dice. Construir ahora sigue siendo, pues, posible y necesario para vivir aunque, como apunta Maillard, ya no hay valor ontológico que conceder a ninguna explicación que nos hagamos. Kālì comprendió esto y se sirvió de una de las posibles herramientas para lograrlo: la mirada deconstructiva. Kālī comprendió a Derrida en aquello de que deshacer es hacer a conciencia, es saber que ya no hay fuera sino dentro, que el afuera está contenido en el dentro y que el dentro es una extensión de diferencias sin centro. Los mundos que la diosa destruye y construye quizá puedan interpretarse como signos diferidos, textos que se transforman en otros textos, huellas de huellas: lenguaje.

Significa esto que: ¿Kālī es posmoderna?, que: ¿Derrida es hinduista? Ni una cosa ni otra y las dos a la vez. En la figura de Kālī se aglutina otro saber que desde las vanguardias se introdujo en el pensamiento occidental y que participó en el diseño de los cauces estéticos y científicos por los que transitó el siglo XX. El pensamiento posmoderno, a su vez, ha continuado amalgamando a sus ovillos hilos de otras madejas para poder seguir produciendo discurso. Así pues, aunque Derrida jamás tuviera noticia del mito de Kālī -dato que desconozco, si bien, en una entrevista, el filósofo francés asegura ser un auténtico neófito en temas orientales-, su trabajo deconstructivo se produce en un contexto intelectual de apertura hacia esas otras enseñanzas que ofrece Oriente y, en general, las regiones políticamente ninguneadas por el etnocentrismo europeo. Aunque Derrida 
no conociera los poderes mitológicos de Kālī, Kālī vierte subrepticiamente su furia hermenéutica en la crítica deconstructiva de Derrida. Ahora bien, es imprescindible remarcar esto: subrepticiamente. Porque los préstamos orientalizados que se puedan detectar en la obra derridiana surgen siempre desde la reducción o síntesis que sobre ellos impuso la tradición europea que los abdujo. Este aspecto es el que diferencia la actitud de Maillard de la del filósofo, porque la escritora sí acude al origen de las tradiciones orientales y rescata de primera mano las influencias que articulan sus trabajos. Aunque ambos autores, cada uno desde su ámbito de creación, canalizan y expanden un pensamiento ritmado en varios de sus ejes -de ahí que ciertos rasgos de Hilos se puedan entender desde la perspectiva derridiana- el camino recorrido se bifurca: Derrida destila sus ideas -para adherirse o para subvertirlas- de las corrientes filosóficas en boga (fenomenología, existencialismo, positivismo lógico, crítica analítica, estructuralismo...) y lo que de oriental haya en ellas es lo que estas escuelas ya habían incluido en sus haberes. Maillard amalgama: por un lado, este mismo poso filosófico; por otro, un regreso a la sabiduría antigua como textura de imbricaciones posmodernas. Este doble préstamo particulariza la escritura de Chantal Maillard dentro del pensamiento contemporáneo -en general-y de las corrientes poéticas y literarias españolas actuales -en particular.

Que la autora recupere la figura de Kālī como signo de la deconstrucción comporta, además, otras desviaciones interesantes: supone una feminización del gesto deconstructivo y al mismo tiempo desplaza la génesis discursiva de éste al seno de un pensamiento mito-poético. La deconstrucción maillardiana es poética y femenina. Como lo es la metáfora de la araña, principio y fin del universo en las Upanishads. Y es que Kālī teje y desteje mundos como la araña sus telas - para la subsistencia-o, incluso podríamos decir, como el observador (en Husos) ve surgir y desaparecer los estados mentales - ¿para la subsistencia también?, sí, inventar al observador es una estrategia para sobrevivir (subsistir), tras haber tocado los límites de la razón.

En la obra de Chantal Maillard, estos aspectos son vectores de una misma configuración estética y epistemológica, y por eso plantean un idéntico quiebro lógico. Preguntarse: ¿hay alguna diferencia entre los mundos de Kālī y la acción de crearlos, no será acaso la diosa una figura externa que aglutina y explica los mundos que modela?, equivale a: ¿quién es la araña?, o: «¿cuál es el huso del observador?» (CH. Maillard 2006, p. 37), en definitiva: ¿hasta qué punto la caída de los meta-relatos no es un nuevo meta-relato? A lo que Derrida contestaría:

Lo que se escribe como différance será así el movimiento de juego que «produce» [...] estas diferencias, estos efectos de diferencia. Esto no quiere decir que la différance que produce las diferencias esté antes que ellas en un presente simple en sí mismo inmodificado, in-diferente. La différance es el «origen» no-pleno, 
no-simple, el origen estructurado y diferente (de diferir) de las diferencias. El nombre de «origen», pues, ya no le conviene. (1998, p. 47).

Las instancias -o estancias mentales- de Kālī, la araña y el observador son orígenes diferidos de los mundos, las telas y los pensamientos que surgen y se diluyen en el entramado, por tanto, orígenes alojados dentro del propio sistema y confeccionados por éste. Maillard aclara: «si es cierto que, como decía Deleuze, "el más cerrado de los sistemas tiene aún un hilo que sube hacia lo virtual y de donde desciende la araña", lo que importa es no perder de vista el hilo y entender que lo virtual no es ninguna realidad primordial o empírea, no; sólo es aquello, llámese lugar o estado de libertad, donde el instinto de ficción puede seguir tejiendo» (2009, p. 207).

\section{REFERENCIAS BIBLIOGRÁFICAS}

BARTHES, R. 2009: El susurro del lenguaje. Barcelona: Paidós.

BOIS, I.-A. «De la tela de araña», en VV. AA., Gego. Desafiando estructuras. Barcelona: MACBA, 2007, pp.45-51.

DERRIDA, J. 1977: Posiciones. Valencia: Pre-Textos. , 1989: La escritura y la diferencia. Barcelona: Anthropos. 1998: Márgenes de la filosofía. Madrid: Cátedra.

FOUCAULT, M. 2008: El pensamiento del afuera. Valencia: Pre-Textos.

MAILLARD, CH. 2001: Filosofía en los días críticos. Valencia: Pre-Textos. , 2004: Matar a Platón. Barcelona: Tusquets.

, 2005: Diarios indios. Valencia: Pre-Texos.

, 2006: Husos. Notas al margen. Valencia: Pre-Textos.

, 2007: Hilos. Barcelona: Tusquets.

, 2009: Contra el arte y otras imposturas. Valencia: Pre-Textos.

, «Las mujeres en la filosofía española», en Iris M. Zavala. (ed.), Breve historia feminista de la literatura española (vol. V). Barcelona: Anthropos, 1998, pp. 240-252.

TRUEBA, V. 2009: «Volver a las palabras (sobre Hilos de Chantal Maillard)», Salina: revista de lletres, 23, pp. 191-200.

VATTIMO, G. 1986: El fin de la modernidad. Barcelona: Gedisa.

Lola Nieto Alarcón es investigadora en la Universidad de Barcelona.

Línea de investigación:

Poesía española contemporánea. 
Publicaciones recientes:

(2010) «La poesía que (se) escribe (con) la filosofía de María Zambrano», en Aurora. Papeles del seminario María Zambrano, $\mathrm{n}^{\circ}$ 11, Barcelona, pp. 134-138.

(2012) «Cantar haikus: Correspondencias entre la escritura de Chantal Maillard y el cine de Andrei Tarkovski», en Sesión no numerada. Revista de letras y ficción audiovisual, $\mathrm{n}^{\mathrm{o}} 2$, Madrid, enero de 2012, pp. 115-137.

http://www.ucm.es/info/sesionnonumerada/index.php/revista/article/viewFile/23/23

Dirección electrónica: eleuceria@ hotmail.com 